\title{
Comparative Analysis of Three Implementation Model of Policies: Case Study in Acid Mine Drainage Management Policy in Indonesia
}

\author{
Franky Armando Hutagalung ${ }^{12 *}$, Tb. Benito A. Kurnani ${ }^{2,3}$ \\ ${ }^{1}$ Environmental and Energy Management Program, University of Twente, The Netherlands \\ ${ }^{2}$ Environment Science Program, Postgraduate School, Universitas Padjadjaran, Indonesia \\ ${ }^{3}$ Centre for Environment and Sustainability Science, Padjadjaran University, Indonesia
}

\begin{abstract}
Policy implementation is one of the main elements of public policy to ensure that policy is successful in resolving all concerns and promoting the efforts made by the organization as a policy implementer. The implementation of public policies can be influenced by several factors, such as limited budget and human resources, lack of socialization, low commitment of authorized officials, including supervision and sanctions that have not been implemented properly. There are many models of public policy implementation, but policy implementation is still ineffective, especially in environmental policies. Some studies have been performed on the development of a policy implementation model with a range of methods and principles, three of them are policy implementation models developed by Van Horn-Van Meter; Grindle; Mazmanian and Sabatier. Those three methods are used respectively according to the existing conditions with different levels of achievement. The objective of this article is to assess the best model of policy implementation related to Acid Mine Drainage management policy of coal mining operations in Indonesia through a comparative study review. The results of the analysis show that the model developed by Mazmanian Sabatier is the most appropriate model to implement the policy of Acid Mine Drainage in Indonesia.
\end{abstract}

\section{Introduction}

Coal production in Indonesia has continued to increase since 2009 with an average annual increase of $9.71 \%$. Indonesia's Ministry of Energy and Mineral Resources published that Indonesia's coal production in 2019 reached 616.16 million tons from the planned coal production target of 489.1 million tons, or with production achievements of $125.98 \%$. The portion of coal exports reached 454.50 million tons $(73.78 \%)$ and to meet domestic demand was 161.66 million tons $(26.22 \%)$. Indonesia is one of the biggest coal exporters in the world due to the high number of exports of coal [1].

Coal mining operations in Indonesia have had a positive impact on the country's income improvement, new employment prospects, electricity supply from steam power plants and cheaper energy for industrial purposes. Apart from having a positive effect, coal mining activities still have negative impacts of its production in environment, such as environmental contamination caused by Acid Mine Drainage (AMD) generation. This contamination is caused by inadequate management of AMD. AMD is a waste created by coal mining, coal processing and coal-mining activities. The quality of AMD derived from coal mining activities should meet the policy requirement before it is released into the environment or water bodies. In order to minimize the effect of the AMD, the Indonesian government has released a range of policies to control the management of the AMD, namely The Decree of State Minister of Environment Number 113 of 2003 concerning the quality standards of wastewater for coal mining activities and The Decree of Minister of Energy and Mineral Resources Number 1827K/30/MEM/2018 concerning Guidelines for Implementing Good Mining Engineering Principles.

While these policies have been released and stipulated by the government, the contamination of the AMD is still continuing. The management policies of the AMD in Indonesia have not been effectively applied. Ideally, the implementation of a policy, in particular policies relevant to the environment, should be carried out by involving all stakeholders in an integrated manner, both in the bureaucracy, sector and industry, as well as in the community. In order to obtain a clear understanding of the implementation of policies related to the environment, it is necessary to recognize that the organization is not the only one responsible for the policies and their implementation for the target groups, but also for the various sectors, such as social political, economic powers, which directly or indirectly influence

\footnotetext{
* Corresponding author: franarman88@gmail.com
} 
the actions of all parties involved. Some framework models of policy implementation have been successfully developed and three of them have often been used to enact policies in Indonesia, namely Grindle Model, Mazmanian - Sabatier Model, Van Horn and Van Meter Model. The author is interested in performing a comparative study of these three implementation models and in determining the best implementation model for the implementation of environmental policies, in particular policies related to the management of AMD in order to reduce the impact of AMD on environment.

\section{Methodology}

The paper followed common literature review from the most applicable literature concerning implementation model of Grindle; Mazmanian and Sabatier; Van Horn and Van Meter. The analyses were performed based on a common comparative analytical framework. Through some comparative analysis approaches such as the analysis of indicators that influence the policy implementation, the paper will draw some conclusions about one of which is the most appropriate model to implement AMD management policy implementation..

\section{Discussion}

\subsection{Acid Mine Drainage}

Acid Mine Drainage (AMD) is produced in the process of mining and extraction of mineral resources and the mass concentration of heavy metal ions varies from a few milligrams to several hundred milligrams per litre, even thousands of milligrams [2]. Mining, refining and purification operations are potential environmental impacts. Mining operations are distinguished by drilling and storage activities [3]. If the substance rises to the surface of the earth, with the production and utilization of different mineral resources, a significant number of sulphur compounds, such as pyrite and pyrrhotite, are exposed to oxidation in a stable atmosphere and then react with water, air and organisms. [2].

The factors that cause the formation of AMD can vary from place to place. AMD that flow on the soil that rich of sulphur, can be generate a high level of sulphide. These factors can be divided into three factors, namely major, secondary and tertiary. Primary influences play a direct role in the formation of mineral oxide sulphide, which are components of acid-forming water. Secondary factors play a role in the ingestion of sulphur oxides in minerals that act as neutralizers. Tertiary factors are physical conditions that which influence the formation of sulphur mineral oxidation, such as the physical condition of the stone, the topography of the mining region, and the atmosphere.

The impact of the AMD depends on the path from which the AMD passes. If AMD flows into aquatic environments, it can become toxins that poison fish and other aquatic organisms. AMD leaching typically results in relatively high amounts of toxic and heavy metals, and when AMD is in contact with aquifers, lakes, rivers, or other parts of the hydrosphere, it can have adverse consequences [4]. If AMD is produced or passes through the soil/land environment, it can pollute and poison soil organisms, including vegetation around the field. Efforts to avoid and monitor AMD are very important in order to minimize the amounts of contaminants found in AMD in compliance with existing environmental quality standards. This effort can be rendered through the management of AMD.

\subsection{The elaboration of three implementation model of policy}

Policies are official announcements on what is planned or supposed to be done or not to be implemented. Policies can be in the form of laws, rules, regulations, decrees, or orders. Policy implementation covers how the policy will be implemented and who will be responsible for implementation. The following offers a description of each of these implementation models.

\subsubsection{Donald Van Meter and Carl Van Horn (1975)}

Implementation model as introduced by Donald Van Meter and Carl Van Horn was the most classic models. This model asserts that implementation runs linearly from public policy, implementor, and the performance of public policy [5]. Van Meter-Van Horn stated that there were five variables which influencing policy implementation: standard and target of policy, resources, communication between organizations and strengthening activities; the characteristics of the implementing agency, and the condition of social, economic and politic [6].

a) Standard and policy [6]

Standard and policy goals must be formulated in a precise and realistic manner so that we can assess the progress rate and the magnitude of the policy that has been enforced. Focus has also been put on the criteria and objectives for the effective implementation of the policy, since the policy standards and objectives set out the overall objectives of the policy decision and go beyond the generalities of the statutory documents in order to include specific and more standards of access to the program, which is why the policy has been effectively adopted, but if such a requirement has been met [7].

b) Resources [6]

Resources in the form of funds or non-human resources or other intentions should be sufficiently available for the implementation of the policy. The performance of policy implementation often depends on the willingness to use the resource. In this perspective, the evaluator should check the feasibility of the application of the policy on the basis of the available resources. If the use of existing resources can be put to good use the performance of every policy can be achieved [8].

c) Communication [6]

Communication between organizations and strengthening activities must go hand in hand with the clarity of standards and principles to ensure the implementation of a policy [8]. The better the 
communication and coordination between the parties involved in an implementation process, the better the implementation, in assumption that errors will be very small to occur and vice versa.

d) The characteristics of the implementing agency [6]

The execution of the bureaucratic system involves the features, norms, and patterns of future and existing relationships. The concentration of attention on implementing bureaucracy involves formal institutions and information organizations would be highly affected by the exact characteristics of the implementing agents.

e) Economic, social and political [6]

Economic, social and political considerations are the last thing that needs to be addressed in order to determine the success of public implementation from the viewpoint of Van Metter-Van Horn. These variables are used to assess the degree to which the external environment contributes to the effectiveness of the public policies that have been developed. In the Van Meter-van Horn implementation models, there are many variables that have an effect on performance that can be seen and become important things in performance so that they can be properly implemented.

\subsubsection{Merilee S. Grindle (1980)}

According to Grindle, in order to determine the effectiveness of public policy implementation, policy variables need to be addressed because with the right policy decisions, people will engage and make the maximum contribution to achieving the desired objective. Grindle points out that the policy substance issues that can impact the "implementability" of the policy are the extent to which the policy aims to bring about improvements in social, political and economic relations; the essence of the benefits (collective/divisible), the degree of behavioural change required, the timeline of the goals to be accomplished (long-range/short-range), the number and dispersion of key objectives [9]. Grindle takes a different view that decision-making policy has developed as a collective discourse for academics of public administration, politics, and policy science in the Third World. Implementation has drawn attention to a broad range of problems, ranging from the availability of adequate resources to the nature of intergovernmental relations. Rule implementation, even if achieved effectively, also requires much more than just a technical way of achieving the aims of a routine project and procedures [10].

The performance of the implementation according to Merilee S. Grindle is influenced by two key variables, the content of policy and the context of policy. Implementation of the public policy model reported by Grindle that the performance of the policy implementation process is also very dependent on the actions of the program that have been designed and adequate funding, as well as being affected by the content of the policy (policy content) and the context of implementation (implementation context) [11].

a) Content of policy

1)Interests that influence policy [12]
The policy could not be separated from the different interests of both the institutional interest and the policy-making interest as an aim of the policy material. This indicator argued that policy implementation definitely entails a great deal of interest, and what we want to know more is to what degree these interests have an impact on implementation.

2) Type of benefit [12]

Grindle argued that the form of benefit created by the policy would have an effect on the implementation of the policy. The substance of the policy aims to illustrate or clarify that there must be a variety of types of benefits that indicate the positive effect that would be produced by the introduction of the policies that are to be implemented. The types of benefits in the policy are acceptable if they are compatible with the anticipated benefits of the target group [13].

3) The degree of change desired [12]

Each policy has an aim that wants to be accomplished. The substance of the policy that will be explained at this stage is the degree to which the reform hoped to be accomplished by the implementation of the policy. The anticipated change (extent of change envisaged) is a further dimension of the policy material. The predicted rate of change in policy would affect the difference in the degree of actions.

4)Policy maker position [12]

Decision-making plays an important role in the execution of the policy, so the place where the policy is to be enforced must be clarified in this section. The region or scope of decision-making (site of decision-making) concerns the degree to which policies are decentralized for their execution or the extent to which power from the centre of politics. The broader the reach of decision-makers in the application of public policy, both geographically and organizationally, the more difficult the policies would be enforced.

5)Policy implementer [12]

The implementation of a policy must be assisted by a knowledgeable and qualified policy-maker to ensure the effectiveness of a policy. The ability of the implementer (institutions or individuals) has an impact on the effectiveness of policy implementation. Involved and highly committed staff actively support the successful implementation of the policy. The functions and duties of policy makers are the most critical conditions for the implementation of the policy in order to ensure the effectiveness of its implementation.

6) Resources [12]

The implementation of the policy must also be accompanied by resources to ensure that it is well enforced. Supporting the resource impacts policy implementation on the degree to which the organization has adequate access to assign the resources needed to execute the policy, both administrative and financial resources.

b) Context of implementation 
1)Power, interest, and strategy of the actors involved [14]

It is therefore important to consider the capabilities or forces, desires and tactics used by the actors concerned in order to promote the implementation of the policy. The policies, sources and positioning of the implementing authority will decide the effective execution of the policy. If it is not properly taken into consideration, it is very likely that the policy to be introduced will fail.

2)Characteristics of institutions and rulers [14] The environment in which the policy is enforced often influences the effectiveness of the implementation of the policy. There is no question that the introduction of the policy would bring controversy to the groups whose interests are affected. Conflict resolution is going to decide "who gets what".

3)Compliance and responsiveness [14]

Policy goals may be accomplished when the implementer listens to the needs of the beneficiaries. Without an appropriate response, the implementer will lose the details required to determine the achievement of the policy and will lose the necessary support for the effectiveness of its implementation.

\subsubsection{Daniel Mazmanian and Paul A. Sabatier (1983)}

Daniel Mazmanian and Paul A. Sabatier designed policy implementation model that called A Framework for Implementation Analysis [15]. Mazmanian stated that the implementation process takes place after a number of stages such as the stage of passing a law, and then the output in the form of implementing a policy decision, and so on until the corrective policy concerned [16]. Mazmanian-Sabatier classified the implementation process of the policy into three variables, namely independent variable, intervening variable, and dependent variable [17].

a) The independent variable consists of difficulties in monitoring the measures of theoretical issues and technical difficulties, diversity of target group, the extent of required behavioural change [18]. Most policy making or formulation is based on causal theory [19]. This theory consists of two parts, the first part of which is the relation between achievement and benchmark or expected outcome. Regulation should not be confused or of different interpretations. In this case, the government should re-analyse the legal product with a degree of consistency and transparency that applies internally and during the implementation of the policy.

b) Intervening variable is the ability to organize the policy implementation mechanism with transparency and continuity of intent, the causal theory and technology used, the precision of the financial allocation, the hierarchical coordination between the executing parties toward an objective, the implementing rules of the implementing agencies, the recruitment of qualified officers. The implementing players should have management skills and political dedication to the goals to be accomplished. Leaders and policy makers should take good steps in the preparation of a regulation. Additionally, other intervening variables are the openness to outsiders, public support, interpersonal constituents, support from higher level authorities, engagement and leadership of law enforcement officials, and non-policy variables that influence the mechanism of implementation of social, economic and technical conditions [19]. Communities that are now open and informed would be relatively easy to embrace the policy change compared to communities that are still closed and conventional. Likewise, technical advancements will lead to the successful implementation of the initiative, as this policy can be socialized and applied with the aid of modern technology.

c) Dependent variable is the stage in the process of implementation of public policies with five steps, consisting of the awareness, coordination, and communication of the agency or the implementing agency in the context of the policy implementation arrangement, the adherence to the goal, the involvement of the outsiders, and the stages leading to the policy revision, in part or in whole, of fundamental properties of the policy.

\subsection{The superiority of Mazmanian-Sabatier Model.}

The implementation model of Grindle is similar to the implementation model of Van Meter-Van Horn. Van Meter-Van Horn and Grindle found the environmental component to be a factor influencing the implementation of the policy. Van Meter-Van Horn has carried out social, political, and economic conditions as one of the factors influencing the implementation of policies, and Grindle has often taken into account the key variables of the policy context or policy setting. Grindle's superiority to Van Meter-Van Horn is based on the policy of policy makers, because the responsiveness of policy makers and policy implementers should be strong if the policy issue affects the interests of policy makers and/or policy implementers. If it is analysed more closely at Grindle's model, we can understand that the uniqueness of Grindle's model lies in its thorough understanding of the policy context, particularly with regard to the implementer, and potential conflicts between the actors and the conditions for the required implementation resources.

If we compare the implementation model of Van Meter-Van Horn, Grindle, and Mazmanian-Sabatier, the variables provided by Mazmanian-Sabatier are more complete than the others. Mazmanian-Sabatier concentrated not only on the internal aspects of policy, but also on the external aspects of policy, such as culture, the diversity of people's behaviour and the essential role of the society. In this situation, the policy implementation is seen from the point of view of the policy actors/implementers who are directly affected and the parties who are not directly affected by the policy implementation. 
Mazmanian-Sabatier emphasized that policy implementation means that forming a policy decision that can be taken in the form of legislation, government rules, executive decisions, and others that refer to the problems that would be resolved by the policy. Mazmanian-Sabatier argued that the policy phases do not help much to understand the policy-making process because separating them into a number of parts is not realistic. From this point of view, therefore, policymaking and execution will merge shortly. Thus, the model developed by Mazmanian-Sabatier used a mixture of a wide spectrum of public and private players interested in a policy problem with similar concerns.

\subsection{Involution of Mazmanian-Sabatier's model in AMD Management}

The identification of all factors, both impact and affected variable, is an important function in the study of the implementation of public policies. All variables and the main elements of each variable along with the relationship of influence to each other. We selected eight of the most important variables of the MazmanianSabatier model for the implementation of AMD policy management[20].

1. Technical difficulties[20]

In its implementation, the management of AMD has its own challenge. Government must coordinate the socialization of companies on the best way and system in the management of AMD and collaborate with the expert on technical implementation. In addition, the government must conduct strict supervision, particularly for companies with low staff capacity, since AMD management policy would be difficult to enforce in this type of business.

There is also a need for qualified and educated human resources to handle AMD. Qualified and trained human capital can be obtained by the specialist by socialization and professional guidance. This condition is fitting for the Mazmanian-Sabatier model, which stated that the performance of the policy implementation was influenced by the degree to which technical criteria had to be met and the availability of such techniques. The availability of certain strategies is affected by the availability of certain technologies that have been developed and will help the achievement of policy implementation effectiveness.

2. Diversity among target group[20]

Diversity among target groups greatly affects the effective implementation of initiatives, such as the diversity of corporate financial conditions. Large-scale businesses with large capital and resources have a better chance of handling AMD relative to small-scale and capital companies. In addition, the educational level of the company's employees in particular those working in the environmental department, would also have an impact on the effective management of AMD. Workers with a comparatively low level of education are likely to face difficulties in understanding AMD management.

3. Scope of expected behaviour change[20]
The opportunity for behavioural improvement means the degree to which policy makers hope to change the actions of their implementers. Policies that deliver long-term benefits are typically more difficult to execute than policies that immediately favour beneficiary groups. As far as AMD management is concerned, the benefits of AMD management will not be immediately felt by the businesses as implementers because the perceived advantages appear to have long-term benefits. Some businesses are also believing that the management of AMD can charge and offer extra costs to the companies. This statement is not entirely valid, because AMD management would help companies in reducing the risk of environmental damage and any environmental issues caused by AMD in the future.

4. Clarity of policy content[20]

Clarity of policy content means that the policy must be explicit and unmistakable, so as not to create a confusion between implementers, for example in AMD management policy, companies must know that they are needed to handle AMD and must also know that certain limits of AMD quality are required before discharge to the environment, so that AMD is secure when it disposed.

Companies are in a position to ensure that they have met the necessary limits by conducting certain tests in an approved laboratory and reporting them to authorized institutions. This is in accordance with the model of Mazmanian-Sabatier that the clearer a policy is, the easier the implementation process will be, because the implementer can easily understand and translate it into the real action.

5. Adequate of theory and technological support[20]

In policy implementation, theoretical support is required to resolve different issues in the policy implementation process. Similar to AMD management policy implementation, workers working in the environmental department should have a strong understanding of AMD management theory from planning to assessment of AMD management.

Linked to technology, large-scale coal mining companies have great opportunities to use technology that can minimize all AMD parameters in order to meet the requirements set by the government. However, the application of technology can often pose issues such as the inability of workers to use technology, equipment and other supporting infrastructure owned by businesses. The implementation of new technologies would often cause challenges, not just the unfamiliar use of technology, but also the unexpected costs incurred by businesses.

6. Coordination among relevant institutions[20]

Policy implementation requires massive coordination and communication among the relevant institutions. In the case of AMD management in Indonesia, the relevant agencies to be involved are the Development Planning Agency, the Energy and Mineral Resources Agency, the Environmental Agency and other relevant agencies. Strong planning and cooperation are required at all levels of company environmental management, e.g. prior to the release of the Energy and Mineral Resources Department's mining 
license, companies should have an environmental license from the Environmental Agency.

In addition, coordination and communication among the appropriate agencies not only in the planning, but also in the supervision and direction of the organization related to environmental management, in particular in the management of AMD. Monitoring and advice is given by cooperation between the Environmental Department and the Energy and Natural Resources Agency and other related agencies.

7. Commitment toward policy objectives[20]

The dedication of the apparatus to the application of the policy can be seen in the enforcement of the policy. Reasonable sanctions can be imposed by the approved apparatus on firms which violate the policy. Policy compliance is perceived to be one of the supporting factors in achieving the goals of policy implementation. Optimal socialization, monitoring and regular coaching should be followed by the provision of stringent sanctions. As regards the management of AMD, sanctions which be placed on companies that are not in a position to comply with the AMD quality level set by the government in the policy.

The verification and determination of the requirements for AMD's quality standards are very difficult to implement, requiring the diligence and professional integrity of the compliance authorities as well as public awareness in the application of the environmental policy provisions.

8. Involvement of the outsiders[20]

The role of outsiders in policy implementation is about supplying information and enabling businesses to handle AMD in order to reach the benchmark. Policies that offer enough resources for the community to be active in enforcing them will be more supportive than policies that do not include the communities. In addition, policies that offer incentives to the implementer are typically easy to gain public support rather than policies that provide disincentives.

\section{Conclusion}

The policy of AMD management should be effectively implemented to avoid some serious consequences especially for environment and living things. Therefore, policy implementation model is needed to execute it. Choosing the best implementation model is significantly necessary to gain the best result in policy implementation. This review aims to contribute to that process. It proposes a simple comparative analysis for explaining variation models in AMD management policy implementation based on three implementation models. In order to achieve the best implementation outcome, the option of the most suitable model is a must. The conclusion of this paper stated that Mazmanian and Sabatier models are the most appropriate in implementing AMD management.

There are some explanations why the Mazmanian and Sabatier models are the most fitting. The first reason is technology incorporation. Mazmanian Sabatier disserts technology as one of the parameters that defines the efficacy of policy implementation. On the other hand, Grindle, Van Horn and Van Meter did not feel that the technical element might have an effect on policy implementation. Technology is the main component of the efficacy assessment of AMD management strategy. Coal companies with higher technologies to handle AMD have a great opportunity to make the policy more successful.

The second reason is the consideration of the extent of technical difficulty. Mazmanian Sabatier had established that the degree of technical complexity had an impact on the implementation of the policy. Technical challenges, such as the manner in which quality requirements are met, the cooperation of policy makers, the implementer and the apparatus. The fourth is public involvement, which is used to calculate the degree to which the public contribution could solve the problems of AMD in coal mining activities in Indonesia. Mazmanian and Sabatier found some data to be more complete than others.

In addition, based on Mazmanian-Sabatier model, it can be concluded that the decision of the policy implementation is not a simple job, since often the policy has broad and ambiguous goals. The evaluator must be able to identify the basic goals of the policy, to consider the government's policy statement, and to know what the policy actually aims to accomplish. In the case of AMD management policy, the policy purpose should be transparent so that the implementers can recognize the basic objectives of AMD management.

Political climate would have emerged through a decision-making process involving political actors, while the administrative process would have arisen through a general process of administrative action which could be examined at a particular policy stage. The political climate depends on its positive or negative aspect. If the climate is optimistic, a policy can have positive reinforcement that can have an impact on the progress of policy implementation. Conversely, if the world has a pessimistic outlook, there would be a conflict of perceptions such that the implementation process is threatened with failure. In Indonesia, the policy on AMD management is relatively influenced by the political climate, especially the state bureaucracy that promotes the AMD policies.

The policy can be implemented effectively where the purpose of these policies has consequences for citizen or interest groups where they have been implemented. The implementation of the policy will run well and achieve the goals if the implementers are assigned or given the task of carrying out the policy. The ability of the implementer is required to reduce the occurrence of difficulties or challenges in the implementation of the policy. Adaptation of the implementation policy of the AMD in Indonesia could take a long time to be accepted. Effective improvements to be made must be accompanied by legislation and regulations, such as the legal basis, competitive workers in the sector, advice and facilities, ties between implementing agencies of AMD management process. 


\section{References}

1. Indonesia National Council of Energy, Indonesia Energy Outlook 2019, (2019).

2. L. Tong, R. Fan, S. Yang, and C. Li, Development and Status of the Treatment Technology for Acid Mine Drainage, Mining Metall Explor., (2020).

3. S. Maharani, P. Purwanto, J. Wassiq Hidayat, and J. Triraharjo, Potential Formation of Acid Mine Drainage in Putra Perkasa Abadi Coal Mining Company - Girimulya Site (BIB), Tanah Bumbu Regency, South Kalimantan, E3S Web Conf., vol. 73, (2018).

4. M. J. Alegbe, O. S. Ayanda, P. Ndungu, A. Nechaev, O. O. Fatoba, and L. F. Petrik, Physicochemical characteristics of acid mine drainage, simultaneous remediation and use as feedstock for value added products, J. Environ. Chem. Eng., vol. 7, no. 3, p. 103097, (2019).

5. D. S. Van Meter and C. E. Van Horn, The Policy Implementation Process: A Conceptual Framework, Adm. Soc., vol. 6, no. 4, pp. 445-488, (1975).

6. G. Valdivieso, The problem of problem structuredness in the Implementation Research literature : a state of the art, no. January, pp. 1-44, (2014).

7. E. Muhangi, Implementation of Public Policy at Primary School Level In Uganda: A Case of Universal Primary Education in Lugusulu SubCounty in Sembabule District, (2017).

8. E. W. Kanmiki and B. O. S. Bempah, Drivers of sound policy implementation: An overview from a theoretical perspective, Policy, Planning, Monit. Eval. Div., no. May, pp. 1-30, (2017).

9. J. Oikarinen, Policy Implementation in International Organization: The Case Study of United Nations in Mozambique, (2018).

10. T. T. Molobela, The Assessment of the 7C Protocols for Policy Implementation in Improving Service Delivery in South African Municipalities, OR Tambo Int. Airpt., no. July, pp. 210-219, (2019).

11. I. M. Mujtahid, S. Suwitri, B. Supriyono, and S. Aripin, A Model of Policy Implementation of Integrated Self-Sufficient City on Transmigration Area (A Case Study in Northern Bengkulu, Bengkulu Province), J. Soc. Sci. Stud., vol. 5, no. 1, p. 23, (2017).

12. S. Mubarok, S. Zauhar, E. Setyowati, and S. Suryadi, Policy Implementation Analysis: Exploration of George Edward III, Marilee S Grindle, and Mazmanian and Sabatier Theories in the Policy Analysis Triangle Framework, J. Public Adm. Stud., vol. 5, no. 01, pp. 33-38, (2020).

13. A. Virawidesma, The Implementation of Government Regulation (PP) Number 81/2012 on The Management of Household Rubbish by The Office of Environmental Services in The Padang City, vol. 3, no. 2, pp. 57-62, (2018).
14. I. Sutristyanto, S. B. S. Haryono, and L. I. Mindarti, Implementation Of Teacher And Lecturer Policy At Vocation Education System Of The Indonesian Navy, Int. J. Sci. Res. Manag., vol. 6, no. 03, pp. 135-142, (2018).

15. P. Sabatier and D. Mazmanian, The Implementation of Public Policy: A Framework of Analysis, (1983).

16. E. Satispi and I. Chandra, Implementation of Bureaucratic Reform in Government of South Tangerang City, (2020).

17. M. Jahan, Gender Streaming in Bangladesh Civil Service : A Critical Study of Women Quota Utilization Thesis Submitted to The Department of Public Administration of Doctor of Philosophy ( PhD ) By Session 2014-15, (2017).

18. Y. Sokseleuy, Policy Implementation: Fishery Policy Related to Local Government Management, Int. J. Pap. Public Rev., vol. 1, no. 2, pp. 15-19, (2020).

19. H. Yuswadi, S. Maarif, D. Program, and E. Java, Disaster Management as Public Policy ( A Case Study of Flood and Landslide Disaster Management Based on Local Wisdom in East Java , Indonesia ), vol. 6, no. 2, pp. 8-12, (2016).

20. Q. Xu and L. Gao, The Causes Analysis of Public Policy Implementation Deviation: Based on a Framework of Paul A. Sabatier and Daniel A. Mazmanian, vol. 157, no. Iceiss, pp. 298-303, (2017) 